\title{
Study on Application of Reading Skills in Critical Reading Teaching
}

\author{
Yuanzhen Wu, Shijun Liu \\ Gongqing College Nanchang University, Gongqing, China \\ lindawyz1986@126.com
}

Keywords: reading skills; critical reading; teaching

\begin{abstract}
: in the teaching of reading, such reading skills as skimming and scanning, inferring, guessing meanings and so on are essential due to its usefulness in helping students doing reading exercises. Yet the problem lies in that they find it difficult to apply these reading skills into practice, even though they are so easy to understand. Thus, this research tries to discuss the role of reading skills in critical reading and the application of these skills into practice.
\end{abstract}

\section{Introduction}

Critical thinking can be defined as a purposeful process of self-regulation and judgment on the correctness of the process, theory, method, background, evidence, and criteria for evaluating knowledge (Facione 2006). And when it is applied to reading, it becomes a high-level understanding of the text, referred to as critical reading (Richard 2003). It consists of the skills of interpretation and evaluation, allowing the reader to distinguish between important and non-essential information, tell facts from opinions, and determine the author's purpose and attitude. At the same time, it is necessary to infer the meaning of the words through reasoning and then fill in the empty parts of the information to get a logical conclusion.

To read critically is to make judgments about how a text is argued. This is a highly reflective skill requiring to stand back and keep some distance from the text one is reading. Try not to read only or primarily for information; instead read looking for ways of thinking about the subject matter.

In short, critical reading means reading and thinking with an open mind, not to simply agree or disagree with ideas in a text, but to discover ideas and information. To be a critical reader doesn't mean criticizing. Readers are to be more concerned with finding the truth than being right and have good reasons for believing some things and disbelieving others, for agreeing with some authors and disagreeing with others. The goal of critical thinking is to evaluate information in an unbiased way. This includes being ready to change one's mind about a subject if the good evidence exists. However, one should also try not to be influenced by unsound evidence. For instance, when reading a piece of fiction critically, use common sense to determine what the writer means, as opposed to what the written words actually indicate.

\section{Role of Reading Skills}

Reading, the input of language, serves as the main approach of language learning. In reading, especially fast reading, reading skills are more often than not, mentioned, which refers to the skills used by language learners to improve the level of reading comprehension during the reading process in order to achieve the efficient reading. In recent years, foreign language scholars and educators at home and abroad have become more and more interested in the reading skills used by foreign language readers in the reading process. They want to know whether these reading skills can be used for teaching to improve readers' understanding ability. Therefore, the study of English reading skills has received much attention and the study of reading skills is of great significance for second language learning and teaching.

In general, reading skills can be categorized into two levels, that is, text-level and word-level. The former includes such reading skills as skimming, scanning, predicting, inferring and recognizing discourse patterns and markers while the latter lays much emphasis on skills like 
guessing word meanings from prefixes, suffixes, compounds, blends and so on, which is related to traditional reading that focuses more on literal meaning of words and sentences. And this paper tries to explore reading skills on text level from a more comprehensive perspective, which also meets the demands of critical reading.

Yang (2015) focuses on the cognitive features of reading teaching in accordance with Bloom's taxonomy, based on which five cognitive levels of questions are put forward, including knowledge, comprehension, application, synthesis and evaluation; among them, the latter four meet the demand of critical reading. And the key point is how to effectively apply reading skills in critical reading and facilitate reading comprehension.

\section{Case study}

From the above discussion, it can be noted that critical reading requires not just the literal meaning of a passage, but has more demands. It follows that reading skills play a crucial role in achieving those purposes, as reading skills focus on summarizing the main idea, finding out details, making requirements and so on. Based on previous reading theories, the teaching of English reading could be considered as a complex cognitive process, and thus the reader, the text and the writer interact with each other to create a communicative process (Xiong 2006). Therefore, the key point is how to help students apply them in critical reading. In other words, reading skills can enhance reading comprehension and the essence of critical reading is better revealed through the application of reading skills.

In this section, an example will be given on how to apply reading skills into actual reading and stimulate the capacity of critical reading. In one reading class, the skills of skimming and scanning are introduced and the difficult point is to distinguish these two skills, as well as relevant tips in carrying them out. In brief, skimming is to get the general idea of a text, namely gist. The tip for skimming is running eyes over a text to get the general meaning instead of stopping at words one doesn't understand as this will only slow down the reading. Next, read the first and last paragraph of a text, and introduction if offered. At the same time, look closely at the topic sentences - the most important sentence of each paragraph. Skimming the written text is like jumping from place to place and one doesn't have to read all the words. For instance, examples known are developing ideas which have been mentioned in the topic sentences, can be jumped over.

On the other hand, scanning requires rapidly running eyes over the text in order to locate specific details; read the question and search for key words or ideas associated with the question. Eyes then move quickly over the page, back and forth, up and down with less reading and more searching, for specific information - a word, a phrase or a number. This final step requires a careful and close reading of the passage after the search in order to find the correct answer.

In explaining the basic introduction of skimming and scanning, it is ironic that few students take notes of these steps of conducting these skills but in the next section of doing relevant exercises, most of them could not think of the tips at all. The main reason is that in learning skills, they all understand them but in actual reading, it is totally different. First, a picture is presented for them to predict the content of the following news report. Then they are assigned with the tasks of skimming and scanning, which should be finished within three minutes: skim the news report and try to give a title to it; what does the word stunt mean? what's the feature of the sanitation technology? The latter two questions are concerning the skill of scanning. The latest news report given is stated as follows:

Billionaire philanthropist and Microsoft founder Bill Gates had his hands full on-stage in Beijing on Nov.6th, showing a jar of human faeces. The stunt was part of his speech at the Reinvented Toilet Expo event - a showcase for new toilet technologies. The showcased products aim to revolutionise sanitation technology by operating off-grid to separate liquid and solid waste and remove harmful by-products.The entrepreneur described the inventions on display as the "most significant advances in sanitation in nearly 200 years".

Short as it is, some give the title like a jar of human faeces, because it is natural to choose the topic from the first sentence, jumping over the following sentences and ignoring the essence of a title, which should comprise all the key information of the whole passage. As to the meaning of 
stunt, most only relate to their previous knowledge, neglecting the function of context. Concerning the last question, some choose the last sentence as the answer while the third one is correct since it distinguishes the new technology from the traditional. Therefore, in such a teaching process, it is urgently needed that teachers combine tips of reading skills in actual reading practice and they ought not to be separated from each other. Furthermore, in the reading practice, students are taught to not only focus on literal meaning of words, but also pay much attention to the structure, cohesion and coherence of the whole passage to achieve critical reading. And in this way, it can enhance the application of reading skills. For instance, the last three sentences all involve similar meanings to invention: reinvented, revolutionise, inventions, and advances. Thus, if attention can be paid to this lexical repetition, it is not difficult to give a title to the passage correctly.

\section{References}

[1] Facione, P.A. Critical Thinking: What it is and Why it counts [M]. California Academic Press, 2006.

[2] Richard Pirozzi: Critical Reading, Critical Thinking: A Contemporary Issues Approach[M]. New York: Addison-Wesley Education Publishers Inc. 2003.

[3] Xiong Lijun, The Inspiration of Reading Theories and Skills on the Teaching of College English Reading, Journal of Xi'an International Studies University, 2006(1), pp. 48-52.

[4] Yang Lifang, The Cognitive Features of Reading Classroom questioning and Critical Thinking Development, Foreign Languages in China, 2015( 2), pp. 68-79. 